\title{
Distally based ulnar artery perforator flap for hand reconstruction and wrist defect closure
}

\author{
Peter Oduor \\ Department of Surgery, Egerton University, Njoro, Kenya \\ Correspondence: oduorpr@gmail.com
}

(c) 2018 P. Oduor. This open access article is licensed under a Creative Commons Attribution 4.0 International License (http://creativecommons.org/licenses/by/4.0/) which permits unrestricted use, distribution, and reproduction in any medium, provided you give appropriate credit to the original author(s) and the source, provide a link to the Creative Commons license, and indicate if changes were made.

East Cent Afr J Surg. 2018 Apr;23(1):38-41 https://dx.doi.org/10.4314/ecajs.v23i1.8

\begin{abstract}
Background

Reconstruction of soft tissue defects of the hand and wrist with exposed tendons, joints, and neurovascular structures challenging for plastic surgeons. Such defects require a flap for coverage to preserve hand and wrist function. We used the distally based ulnar artery perforator flap for reconstruction in patients with soft tissue deformities and defects of the wrist and hand.

Methods

Between June 2015 and August 2017, 8 patients were operated upon to correct deformities of the hand and wrist using the distally based ulnar artery perforator flap. Their ages ranged from 1.5 to 32 years, and the male-to-female ratio was 1:1. Five of the patients had post-burn contractures, and the remaining were post-trauma, with 1 gunshot wound and the other 2 resulting from road traffic accidents. The flap was islanded in 3 patients and pedicled in 5.
\end{abstract}

\section{Results}

All of the flaps survived, and donor site defects in all patients were covered with split-thickness skin grafts. There was minimal donor site morbidity.

\section{Conclusions}

The distally based ulnar artery perforator flap is a convenient and reliable flap for reconstruction of soft tissue defects and postburn contractures of the hand and wrist. Its main advantages are that it is a single-stage procedure with no sacrificing of major vessels.

Keywords: ulnar artery, perforators, hand and wrist, Kenya

\section{Introduction}

Soft tissue defects of the hand and wrist with exposed tendons, nerves, joints, and bone represent a challenge to plastic and reconstructive surgeons. Split-thickness skin grafting has a limited role in these defects. Such defects necessitate flap coverage to preserve hand function, protect vital structures, and allow early rehabilitation. This can be done with a local flap, distant flap, or free flap. There has been a significant leap forward with the introduction of perforator flaps, ${ }^{1}$ which were first described in 1988 by Becker and Gilbert as fasciocutaneous flaps. ${ }^{2-4}$ The main advantage of perforator flaps is the minimization of donor site morbidity; the flap is reliable and easy to harvest. ${ }^{2}$ We used the distally based su- perficial ulnar artery perforator flap, based on the dorsal ulnar artery branch, for wrist and hand defects. This is supplied by the ascending branch of the dorsal ulnar artery, which is a major branch of the ulnar artery in the distal forearm.

The importance of the flap lies in the possibility of mobilization of tissue for reconstruction of the hand without losing a major vascular axis. The flap can be raised as a pedicled or a true island flap. ${ }^{5}$

\section{Anatomy}

The flap is based on the dorsal branch of the ulnar artery. The pivot point of the flap is approximately $4 \mathrm{~cm}$ proximal to the pisiform bone in a line drawn between this bone and the medial epicondyle of the humerus; that is the position 
Table 1. Patient demographics and case details

\begin{tabular}{|c|c|c|c|c|}
\hline $\begin{array}{l}\text { Patient } \\
\text { no. }\end{array}$ & $\begin{array}{c}\text { Age } \\
\text { (years) }\end{array}$ & Sex & Location of defect & $\begin{array}{l}\text { Type of } \\
\text { flap }\end{array}$ \\
\hline 1 & 18 & M & Gunshot wound volar wrist & Islanded \\
\hline 2 & 25 & $\mathrm{~F}$ & Post-burn contracture wrist with extension deformity (defect on the dorsum of the hand) & Islanded \\
\hline 3 & 18 & $\mathrm{~F}$ & Post-burn contracture with flexion deformity left wrist and thumb & Pedicled \\
\hline 4 & 1.5 & $\mathrm{~F}$ & PBC right wrist with extension deformity & Pedicled \\
\hline 5 & 28 & M & Post traumatic defect dorsum of hand & Pedicled \\
\hline 6 & 4 & $\mathrm{~F}$ & Post-burn contracture left wrist with extension deformity & Pedicled \\
\hline 7 & 16 & M & Post-burn contracture with flexion deformity wrist and 3rd-5th fingers left hand & Islanded \\
\hline 8 & 32 & M & $\begin{array}{l}\text { Road traffic accident with injury to extensor carpi radialis longus and extensor carpi } \\
\text { radialis brevis and degloving of the skin on the dorsoradial side of the wrist }\end{array}$ & Pedicled \\
\hline
\end{tabular}
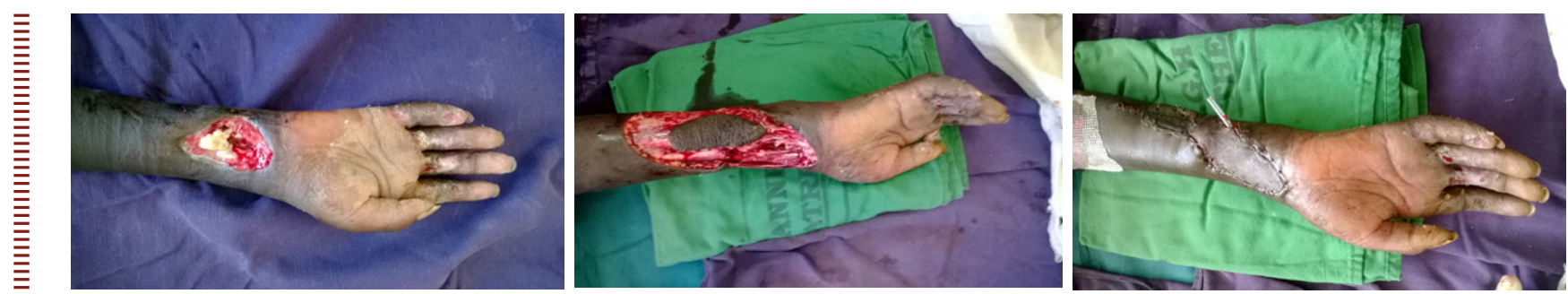

Figure 1. Patient no. 1 (gunshot wound on the volar wrist); from left to right - wound before debridement; intraoperatively after raising the transposing flap; immediately postsurgery with tube drain in situ
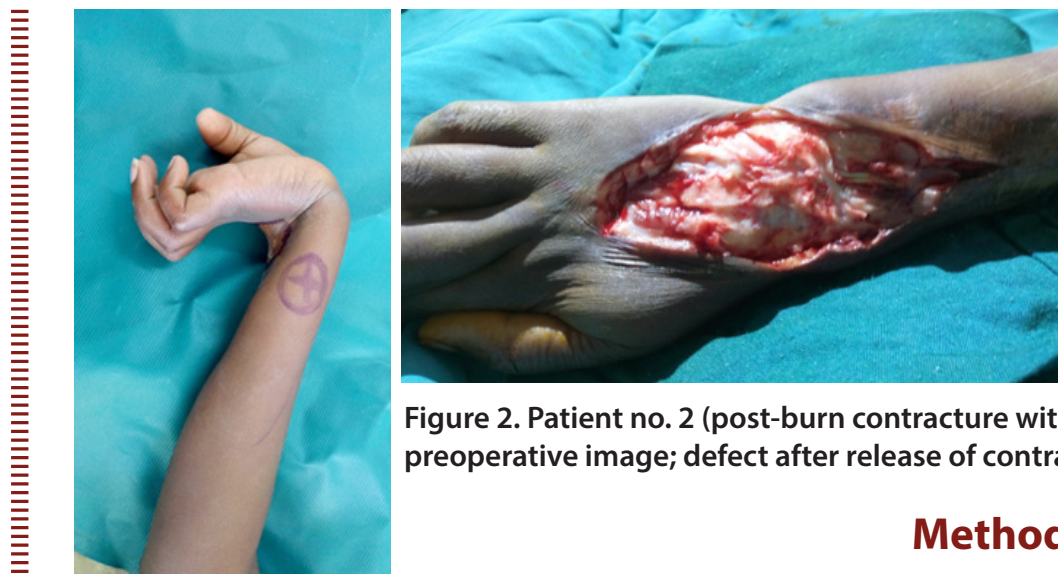

Figure 2. Patient no. 2 (post-burn contracture with extension deformity); from left to right preoperative image; defect after release of contracture; immediately postsurgery of the dorsal ulnar artery origin. Near the pivot point, the flap is raised between the flexor carpi ulnaris (FCU) and extensor carpi ulnaris (ECU) tendons. The dissection begins at the apex of the flap. The flap is raised with the fascia over the muscle belly of the FCU. The dorsoulnar artery has 2 committing veins representing venous drainage of the flap., ${ }^{3,5}$ The anterior limit of the flap is the palmaris longus tendon, and the posterior limits extend to the extensor digitorum communis of the fourth digit, producing a width of 5 to $9 \mathrm{~cm}$. The length can be extended up to about $20 \mathrm{~cm}^{6}{ }^{6}$

\section{Methods}

Between June 2015 and August 2017, 8 patients were operated upon, out of which 5 had post-burn contractures, 1 had a gunshot wound, and 2 were injured in road traffic accidents. There were 4 males and 4 females, ranging in age from 1.5 to 32 years.

Preoperatively, a handheld Doppler was used to identify the perforator vessel on which the flap was to be based.

The surgical procedure was performed in all the cases under general anaesthesia and loupe magnification. A tourniquet was used in all cases to minimize bleeding during surgery. The wound bed was prepared through debridement and reverse planning of the flap performed. Dissection started from the ulnar side of the wrist and forearm from proximal 

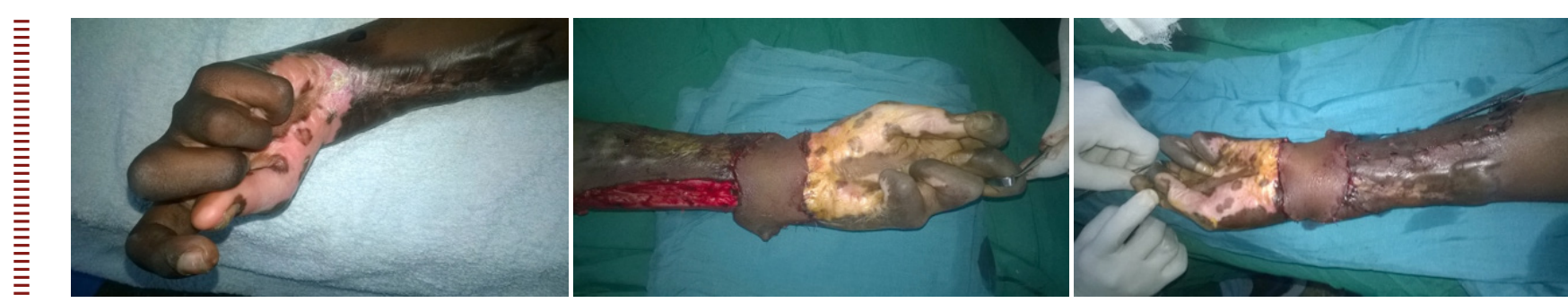

Figure 3. Patient no. 7 (post-burn contracture with flexion deformity of the wrist and third to fifth fingers on the left hand); from left to right - preoperative image; intraoperatively with the wrist contracture released; flap inset and donor site covered with skin graft
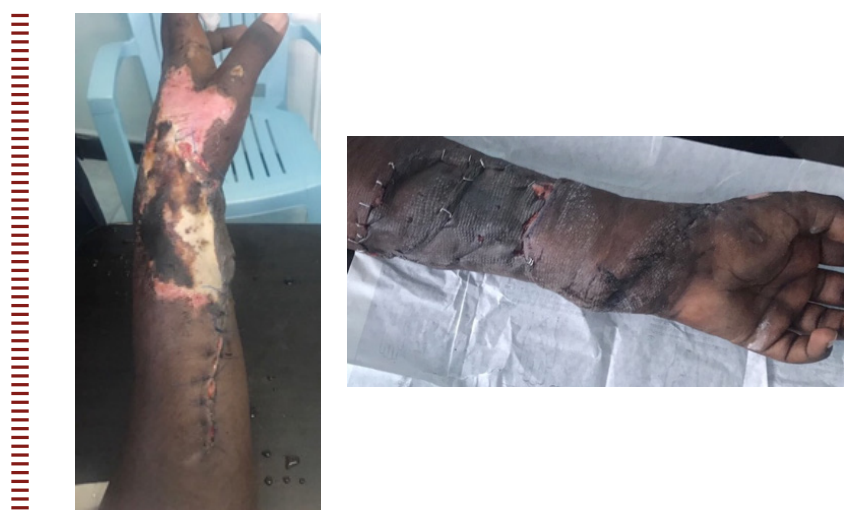

Figure 4. Patient no. 8 (road traffic accident with injury to extensor carpi radialis longus and extensor carpi radialis brevis and degloving of the skin on the dorsoradial side of the wrist); from left to right - preoperative image and immediately postoperative image after excision of the degloved skin and flap cover

to distal, including the fascia. The flap was then transposed onto the defect and the donor site covered with split-thickness skin grafts in all the patients. The flap was islanded in 3 patients and pedicled in 5 .

A drain was placed beneath the flap, and the hand was immobilized in a neutral position using a plaster of Paris cast. Postoperatively, the hand was elevated to reduce venous congestion. The drain was removed after a mean of 3 days.

\section{Results}

The flaps survived in all the patients. There was partial loss of the skin graft in 2 of the patients and flap tip necrosis in 1 patient; these resolved with regular wound dressings. All patients were satisfied with the functional and cosmetic outcome.

\section{Discussion}

Soft tissue defects of the wrist and hand offer a challenge to the reconstructive surgeon. Local, distant, and free flaps provide options for defect cover.

While free flaps require expensive equipment and expertise that are not readily available, distant flaps tend to be bulky and require multiple surgical procedures.

Local flaps are usually limited in size and mobility but offer relatively simple and safe wound coverage. They also allow the patient freedom for occupational therapy to be com- menced early. ${ }^{5,8}$ Among the local flaps are the reverse radial island flap, reverse ulna island flap, and distally based ulnar artery perforator flap. The disadvantage of the reverse ulnar and radial artery island flaps is that they sacrifice the vascular supply to the hand.

The distally based ulnar artery perforator flap was first described by Becker and Gilbert in 1988 and relies on the dorsal branch of the ulnar artery. Its advantages are that it is a safe, simple, and effective 1-stage procedure that provides thin, pliable, good-quality skin with a robust blood supply. ${ }^{2,8}$ The main disadvantages are donor site morbidity and the short pedicle, which results in a relatively limited arc of rotation, ${ }^{1,7,8}$ but this tends to mature well with time unless there is loss of the skin graft.

We decided to present these cases to show our region the potential advantages of the dorsal ulnar artery perforator flap. This is a flap that could be of use in various challenging situations for covering soft tissue defects of the hand and wrist.

\section{Conclusions}

The distally based ulnar artery perforator flap is versatile, safe, and reliable. It provides single-stage reconstruction without sacrificing the major arteries of the forearm. It is suitable for closure of small or medium-sized defects without donor site morbidity. This flap is an excellent local option for soft tissue coverage of hand and wrist defects that preserves a major vascular axis. It is a convenient, reliable, and easy-to-manage single-stage technique for reconstructing soft tissue defects of the hand and wrist.

\section{Competing interests}

The author declares that he has no competing interests related to this work. 


\section{References}

1. Martin D, Bakhach J, Casoli V, Pellisier P, CiriaLlorens G, Khouri RK, et al. Reconstruction of the hand with forearm island flaps. Clin Plast Surg. 1997 Jan;24(1):33-48.

2. Becker C, Gilbert A. [The cubital flap]. [Article in French]. Ann Chir Main. 1988;7(2):136-42

3. Becker C, Gilbert A. The ulnar flap description and applications. Eur J Plast Surg. 1988;11(2):79-82. doi: 10.1007/BF00299217.
4. Holevich-Madjarova B, Paneva-Holevich E, Topkarov V. Island flap supplied by the dorsal branch of the ulnar artery. Plast Reconstr Surg. $1991 \mathrm{Mar} ; 87(3): 562-6$

5. Abd Al Moktader M. Superficial dorsal ulna artery flap for hand and wrist coverage. Egypt, J Plast Reconstr Surg. 2010 Jul;34(2):219-22.

6. Antonopoulos D, Kang NV, Debono R. Our experience with the use of the dorsal ulnar artery flap in hand and wrist tissue cover. J Hand Surg Br. 1997 Dec;22(6):739-44.
7. Karki D, Singh AK. The distally-based island ulnar artery perforator flap for wrist defects. Indian J Plast Surg. 2007 Jan-Jun;40(1):12-7. doi: 10.4103/0970-0358.32657.

8. Khan MM, Yaseen M, Bariar LM, Khan SM Clinical study of dorsal ulnar artery flap in hand reconstruction. Indian J Plast Surg. 2009 Jan-Jun;42(1): 52-7. doi: 10.4103/09700358.53012 